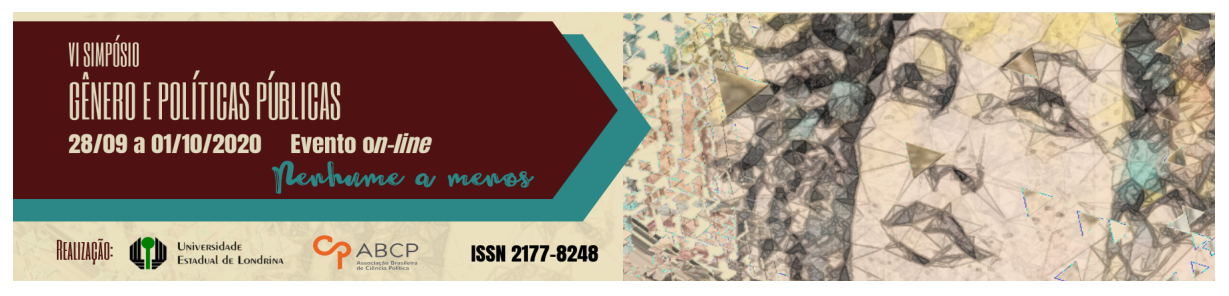

\title{
A presença da mulher na direção do cinema brasileiro contemporâneo
}

\author{
Fernando Antonio Prado Gimenez ${ }^{1}$
}

\section{Resumo}

Entre as desigualdades da indústria do cinema no Brasil, se destaca a baixa participação feminina na realização de obras audiovisuais. Esta questão tem atraído a atenção de estudiosos do campo no Brasil. O tema, também, foi foco de ação da Agência Nacional de Cinema (ANCINE) que, em novembro de 2017, instalou a Comissão de Gênero, Raça e Diversidade da ANCINE. O objetivo do artigo é descrever a evolução da presença feminina na produção de cinema contemporâneo no Brasil. Assim, foi realizada análise de dados disponíveis no Observatório Brasileiro do Cinema e do Audiovisual. A partir desses dados se tratou de aspectos da presença da produção feminina no mercado de cinema brasileiro, em termos de número de filmes, público e distribuição. Além disso, com base em entrevistas de diretoras de cinema brasileiras, publicadas em livro de Lúcia Nagib, buscou-se descrever a visão que mulheres têm de sua inserção neste mercado.

Palavras-chave: cinema brasileiro; direção; mulheres

\section{The presence of women in the production of the contemporary Brazilian cinema}

\begin{abstract}
Among the inequalities in the Brazilian film industry, the low female participation in audiovisual works stands out. This issue has attracted the attention of scholars in the field in Brazil. The theme, too, was the focus of action of the National Film Agency (ANCINE), which, in November 2017, installed the ANCINE Gender, Race and Diversity Commission. The objective

1 Universidade Federal do Paraná, Doutor em Administração pela University of Manchester e Especialista em Cinema pela Universidade Tuituti do Paraná, fapgimenez@gmail.
\end{abstract}

GT 14 - Gênero, trabalho e sindicalismo 
of the paper is to describe the evolution of the female presence in contemporary cinema production in Brazil. Thus, an analysis of data available at the Brazilian Observatory of Cinema and Audiovisual was carried out. Based on these data, aspects of the presence of female production in the Brazilian cinema market were addressed, regarding number of films, audience and distribution. In addition, based on interviews with Brazilian film directors, published in a book by Lúcia Nagib, we sought to describe the vision that women have of their insertion in this market.

Keywords: brazilian cinema; direction; women

\section{Introdução}

Entre as inúmeras desigualdades da indústria do cinema no Brasil, se destaca a baixa participação feminina na realização de obras audiovisuais. Esta questão tem atraído a atenção de estudiosos do campo no Brasil. Desde 1930, já se tem registros da presença de mulheres dirigindo filmes no Brasil, com a realização de $\mathrm{O}$ mistério do dominó preto por Cléo de Verbena (ARAÚJO, 2017; BARBOSA, 2019). Também nos anos 30 e 40 do século passado, a história registrou a participação de Carmen Santos, Gilda Abreu e Gita de Barros entre as mulheres pioneiras do cinema brasileiro seja como atrizes, roteiristas e diretoras (BARBOSA, 2019).

No caso específico da direção, Holanda (2017a) comenta sobre a inexistência de registro de filmes dirigidos por mulheres nos anos 60, época em que, segundo a autora, o cinema brasileiro alcançava fama internacional, enquanto, conforme registrado por Munerato e Oliveira (1982, apud Holanda (2017a), na década de 50 houve oito filmes longas dirigidos por mulheres. No começo da década de 70, Schvarzman (2017) aponta a presença de Gilda Bojunga na direção de documentários, sendo seu primeiro feito em 1971. Nessa década também, como evidenciado em Holanda (2017a), há outras mulheres que atuaram na direção de filmes brasileiros que chegaram às salas de cinema. Mas, mesmo quando há registros de mulheres no fazer cinematográfico brasileiro, esta sempre foi minoritária quando comparada à dos homens. 
Alves, Alves e Silva (2011) trazem um panorama da presença feminina no cinema brasileiro de 1961 a 2010. Os dados retratam uma crescente participação das mulheres nas funções de direção, roteirista, produção e fotografia ao longo do tempo. Além das estatísticas, o texto traz um histórico sobre a presença de mulheres cineastas desde os primórdios do cinema brasileiro.

Nagib (2012) segue outra trilha ao comentar a participação das mulheres no cinema brasileiro a partir da Retomada, em 1995. Para ela, além das diferenças de sexo, raça ou etnia, uma análise mais frutífera do cinema feminino no Brasil se dá quando se percebe que é a partir da Retomada, com a entrada mais numerosa de mulheres na função de diretoras que se acentua "a disseminação do trabalho colaborativo e da autoria compartilhada" (NAGIB, 2012, p. 17), traço marcante da presença feminina no cinema brasileiro para ela. Para Holanda (2017a, p. 45), a referência ao cinema feito por mulheres deve considerar "um amplo espectro de possibilidades de expressões, que considera as diferenças entre as mulheres, mas entende que estão reunidas sob experiências, até certo ponto comuns".

Esta maior presença de mulheres cineastas a partir da Retomada foi observada também por Desbois (2016). Holanda (2017b) confirma que, apesar das mulheres fazerem menos filmes que os homens, a produção feminina de filmes no Brasil tem aumentado. No entanto, para a autora, a maioria dos filmes recebe pouca ou nenhuma atenção.

Alves e Coelho (2015) apontaram um aspecto muito significativo em relação à presença de mulheres na direção de filmes. As autoras lembraram que o tema dessa presença tinha ganhado notoriedade em anos anteriores, inclusive com a ocorrência de protestos de movimentos feministas criticando a raridade de filmes dirigidos por mulheres nos principais festivais de cinema do mundo. Como apontado por elas, "a presença de mulheres era exatamente isso, um fato raro, as mulheres que se aventuravam na direção 
cinematográfica eram exceções" (ALVES; COELHO, 2015, p. 171). Todavia, Hollanda (2017, p. 7) contrapõe a esta visão, o fato de que:

o cinema feito por mulheres, atrizes, diretoras e produtoras, no Brasil, vem de longa data e percorre uma trajetória invulgar na história de nossa cinematografia. Entretanto, historicamente, o trabalho das mulheres tende a ser silenciado ou, de alguma forma minimizado, procedimento que, no campo do cinema, não tem se mostrado muito diferente.

Por outro lado, o tema foi foco de ação da Agência Nacional de Cinema (ANCINE) que, em novembro de 2017, instalou a Comissão de Gênero, Raça e Diversidade da ANCINE. O objetivo da comissão é desempenhar atividades voltadas à promoção da inclusão, diversidade e igualdade de oportunidades no âmbito da ANCINE. Como visto a comissão foi criada para tratar de grupos sociais que extrapolam a questão feminina. Meu entendimento é que esta ação seja fruto ou reflexo, ainda que tardio, das transformações em políticas públicas apontadas por Cines e Gurgel (2008). Neste sentido, as autoras comentaram que,

a partir de meados da década de 1980 houve uma forte iniciativa dos governos, em âmbito continental, e no Brasil, em particular, quanto à incorporação das relações sociais de gênero como base ou como "tema transversal" em suas ações ou políticas públicas (CISNE; GURGEL, 2008, p. 78).

Relacionada a esta temática, encontra-se no site do Observatório Brasileiro do Cinema e do Audiovisual uma publicação sobre a presença feminina no mercado de audiovisual brasileiro (ANCINE, 2019). O foco principal do documento está nos resultados referentes a 2016 e 2018, que complementam os dados divulgados anteriormente sobre o período entre 2009 e 2015 (ANCINE, 2017a, 2017b).

Mas, no caso específico dos lançamentos brasileiros voltados paras as salas de cinema, o documento mais recente traz informações 
sobre a presença feminina em cargos de direção relativas ao período 2014-2018. Assim, pode-se perceber que, ao longo desses anos, a presença feminina tem crescido gradativamente, passando de $14 \%$ em 2014 para 22\% em 2018, quando miramos os cargos de direção. Se adicionarmos os filmes que tiveram direção mista, isto é, compartilhada entre mulheres e homens, estes totais foram de $30 \%$ e $45 \%$, respectivamente. Esses números mostram, ainda, que a presença feminina isolada na direção de filmes brasileiros lançados nos cinemas é muito menor do que a dos homens que foi de $70 \%$ em 2014 e 55\% em 2018.

Outro dado interessante desse documento diz respeito à participação no público total dos filmes dirigidos pelas mulheres. Nesse caso, a presença feminina tem sido muito pequena, 4\% em 2014 e $2 \%$ em 2018. Em 2016, no entanto, houve um pico de participação dos filmes dirigidos por mulheres no público de cinema que chegou a $34 \%$. Esse desempenho em 2016 pode ser devido, especialmente, ao sucesso de dois filmes dirigidos por mulheres que ficaram entre os de maior público nos cinemas naquele ano. O filme É fada! de Cris D'Amato teve um público de 1.722 .069 espectadores e Um namorado para minha mulher, de Júlia Rezende, foi visto por 665.999 pessoas. Ambos foram distribuídos pela Downtown Filmes que detém a maior parcela de público dos lançamentos de filmes brasileiros (GIMENEZ, 2019).

Neste contexto, ressalto a opinião de Holanda e Tedescco (2017, p. 9) que reforçam a necessidade de aprofundamento de estudos nesta temática, visto que a literatura não tem dedicado a devida atenção à questão:

Especificamente no cinema, percebe-se um aumento na demanda por estudos sobre a participação da mulher no audiovisual brasileiro, e a subsequente constatação de que o que foi publicado até agora é mínimo se comparado ao papel desempenhado por ela, em diversas funções, na cinematografia nacional (HOLANDA; TEDESCCO, 2017, p.9). 
O objetivo do artigo é, com base em dados secundários, descrever a evolução da presença feminina na produção de cinema contemporâneo no Brasil. Para essa finalidade, foram realizados levantamento e análise de dados do Observatório Brasileiro do Cinema e do Audiovisual. Os dados tratados se referem a número de filmes, público, renda e acesso ao mercado distribuidor. Além desse enfoque quantitativo, fiz uso de dados de natureza qualitativa incorporados nos depoimentos de mulheres diretoras de cinema que foram apresentados em Nagib (2002). O período compreendido neste livro vai de 1994 a 1998, com relatos de 16 mulheres.

Estruturei o artigo em mais três seções, além dessa introdução. Na próxima seção, apresento a análise quantitativa da presença de mulheres na direção de filmes brasileiros entre 1995 e 2019. Em seguida, abordo os depoimentos das cineastas entrevistadas por Lúcia Nagib, buscando ressaltar as nuances do fazer cinematográfico na visão dessas mulheres. Por fim, na última seção, aponto a contribuição do estudo aqui relatado para o campo, bem como suas limitações e sugestões de estudos futuros.

\section{Dados estatísticos sobre a atuação da mulher na direção de filmes brasileiros}

A análise dos dados disponibilizados pelo Observatório Brasileiro do Cinema e do Audiovisual - OCA (oca.ancine.gov.br), me permitiu traçar um panorama da presença da mulher na direção de filmes brasileiros entre 1995 e 2019. Para o período entre 1995 e 2018, os dados estão registrados em arquivo intitulado Listagem de Filmes Brasileiros lançados 1995 a 2018. Para o ano de 2019, as informações preliminares foram colhidas no arquivo Resultados Mensais do Cinema Brasileiro.

No primeiro arquivo há dados detalhados para 1.742 filmes brasileiros lançados nas salas de cinema entre 1995 e 2018. Esses dados incluem: ano de lançamento; certificado de produto brasileiro (CPB); 
título; direção; gênero; empresa produtora brasileira majoritária e unidade da federação; empresa produtora minoritária brasileira e unidade da federação; distribuidora; máximo de salas; renda; e público.

No segundo arquivo, entre outras informações, encontra-se a listagem de todos os filmes exibidos nas salas de cinema brasileiras em 2019. Esta listagem parcial indicava que, além de filmes que já tinham sido lançados em anos anteriores, foram exibidos 129 filmes brasileiros lançados entre 17/01/2019 e 19/12/2019. Todavia, as informações sobre estes filmes não são exatamente as mesmas do primeiro arquivo. Nesta listagem estão disponíveis dados sobre: título da obra; certificado de produto brasileiro ( $\mathrm{CPB}$ ); gênero; data de lançamento; distribuidoras; público; e renda. Não estão disponíveis as informações sobre empresas produtoras, unidades da federação, máximo de salas e direção.

Além disso, no documento Informe Anual Preliminar Salas de Exibição 2019, é informado que em 2019, foram lançados 171 filmes brasileiros, ou seja, 42 filmes a mais do que a informação disponível no segundo arquivo mencionado acima. Dessa forma, para tentar completar os dados sobre 2019, fiz uma busca no site Filme B (filmeb.com.br) que disponibiliza, entre outras, informações sobre as estreias de filmes brasileiros em cada ano. Este esforço permitiu que, para 2019, eu localizasse mais 47 filmes brasileiros. Assim, o total de filmes brasileiros lançados em 2019, cujos dados foram localizados por mim, chegou a 176 filmes, cinco a mais do que o informado no OCA.

Com base nessa relação total de 1.918 filmes, fiz uma listagem dos nomes de todos os diretores e diretoras informados. O resultado mostrou que, nesses 25 anos, 1.285 cineastas conseguiram lançar ao menos um filme nos cinemas brasileiros. Os nomes foram, então, analisados para identificar se eram mulheres ou homens. Nos casos em que os nomes não fossem claramente masculinos ou femininos, fiz uma busca na internet para identificar caso a caso. Ao cabo, foram identificadas 262 mulheres e 1.023 homens, ou seja, pouco mais de um 
quarto dos cineastas que lançaram filmes brasileiros entre 1995 e 2019 são mulheres (25,6\%).

Minha intenção nesta seção é descrever diversos aspectos da presença das mulheres nesse mercado. Começo mostrando a participação delas na direção de filmes ao longo desses 25 anos. No gráfico 1, pode-se ver a evolução do número de homens e mulheres que lançaram filmes nas salas de cinema do Brasil nesse período. Como pode ser notado, embora o número de mulheres tenha aumentado ao longo desse período, este crescimento não conseguiu acompanhar o crescimento do número de homens dirigindo filmes brasileiros lançados em cinemas. A tabela 1 mostra a variação na proporção de mulheres e homens ao longo dos anos.

Gráfico 1 - Evolução da presença de homens e mulheres na direção de filmes brasileiros

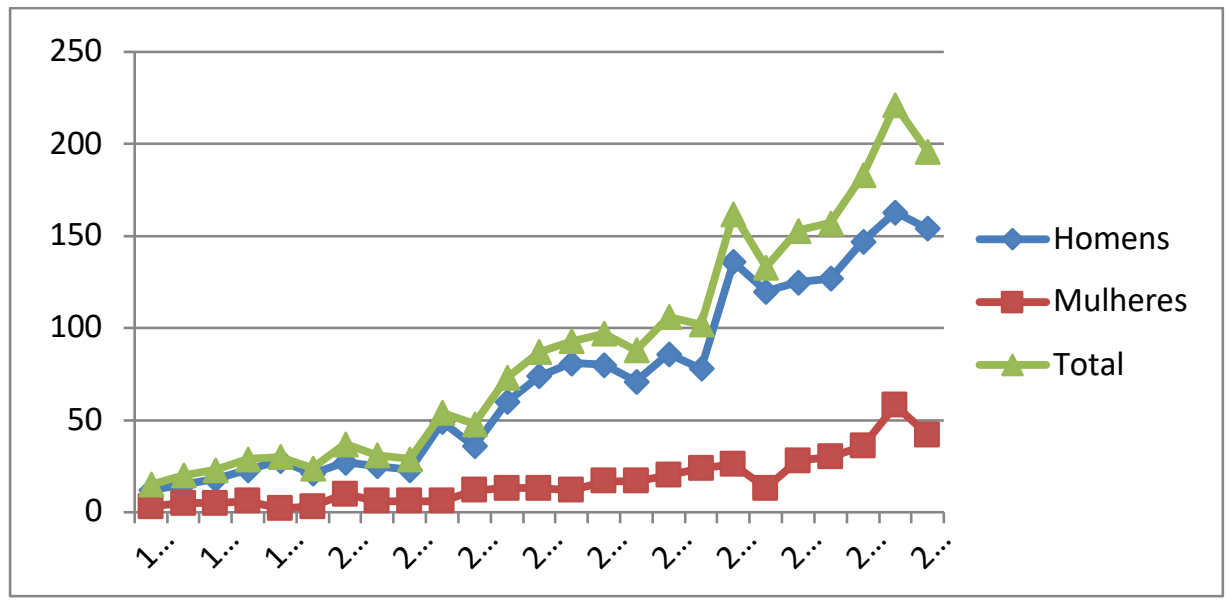

Fonte: O autor (2020).

Independentemente de serem dirigidos por mulheres ou homens, a exibição de filmes brasileiros no mercado de cinema não é uma tarefa fácil. Dois terços dos cineastas (66,5\%), ou seja, 855 diretores ou diretoras conseguiram exibir apenas um filme nestes 25 anos. Outros 16,3\% (210) conseguiram ter apenas dois filmes exibidos nas salas de cinema no Brasil. Com três filmes exibidos no período, 
esse percentual caiu para 6,6\% (85). Dessa forma, no conjunto, foram apenas 135 cineastas, pouco mais de 10\%, que lançaram quatro ou mais filmes nesse período.

Tabela 1 - Número de homens e mulheres na direção de filmes brasileiros

\begin{tabular}{c|c|c|c|c|c|c|c|c|c}
\hline Ano & Homens & Mulheres & $\begin{array}{c}\text { \% } \\
\mathbf{M} / \mathbf{H}\end{array}$ & Total & Ano & Homens & Mulheres & $\begin{array}{c}\% \\
\mathbf{M} / \mathbf{H}\end{array}$ & Total \\
\hline 1995 & 12 & 3 & 25,00 & 15 & 2008 & 81 & 12 & 14,81 & 93 \\
\hline 1996 & 15 & 5 & 33,33 & 20 & 2009 & 80 & 17 & 21,25 & 97 \\
\hline 1997 & 18 & 5 & 27,78 & 23 & 2010 & 71 & 17 & 23,94 & 88 \\
\hline 1998 & 23 & 6 & 26,09 & 29 & 2011 & 86 & 20 & 23,26 & 106 \\
\hline 1999 & 28 & 2 & 7,14 & 30 & 2012 & 78 & 24 & 30,77 & 102 \\
\hline 2000 & 21 & 3 & 14,29 & 24 & 2013 & 136 & 26 & 19,12 & 162 \\
\hline 2001 & 27 & 10 & 37,04 & 37 & 2014 & 120 & 13 & 10,83 & 133 \\
\hline 2002 & 25 & 6 & 24,00 & 31 & 2015 & 125 & 28 & 22,40 & 153 \\
\hline 2003 & 23 & 6 & 26,09 & 29 & 2016 & 127 & 30 & 23,62 & 157 \\
\hline 2004 & 49 & 6 & 12,24 & 54 & 2017 & 147 & 36 & 24,49 & 183 \\
\hline 2005 & 36 & 12 & 33,33 & 48 & 2018 & 163 & 58 & 35,58 & 221 \\
\hline 2006 & 60 & 13 & 21,67 & 73 & 2019 & 154 & 42 & 27,27 & 196 \\
\hline 2007 & 74 & 13 & 17,57 & 87 & Total & 1023 & 262 & 25,61 & 1285 \\
\hline
\end{tabular}

Observação: o total não é a soma de cada coluna, pois há cineastas com filmes em vários anos.

Fonte: $\mathrm{O}$ autor (2020).

Os dados, quando segregados por sexo, indicam que as mulheres têm um desempenho um pouco inferior aos homens na quantidade de filmes lançados no mercado. Assim, enquanto 11,1\% (114) homens lançaram quatro ou mais filmes entre 1995 e 2019, as mulheres que atingiram esta marca foram apenas 21 (8,0\%). No gráfico 
2, nota-se que a presença proporcional das mulheres vai diminuindo conforme aumenta o número de filmes lançados no período.

Gráfico 2 - quantidade de filmes lançados sob a direção de homens e mulheres

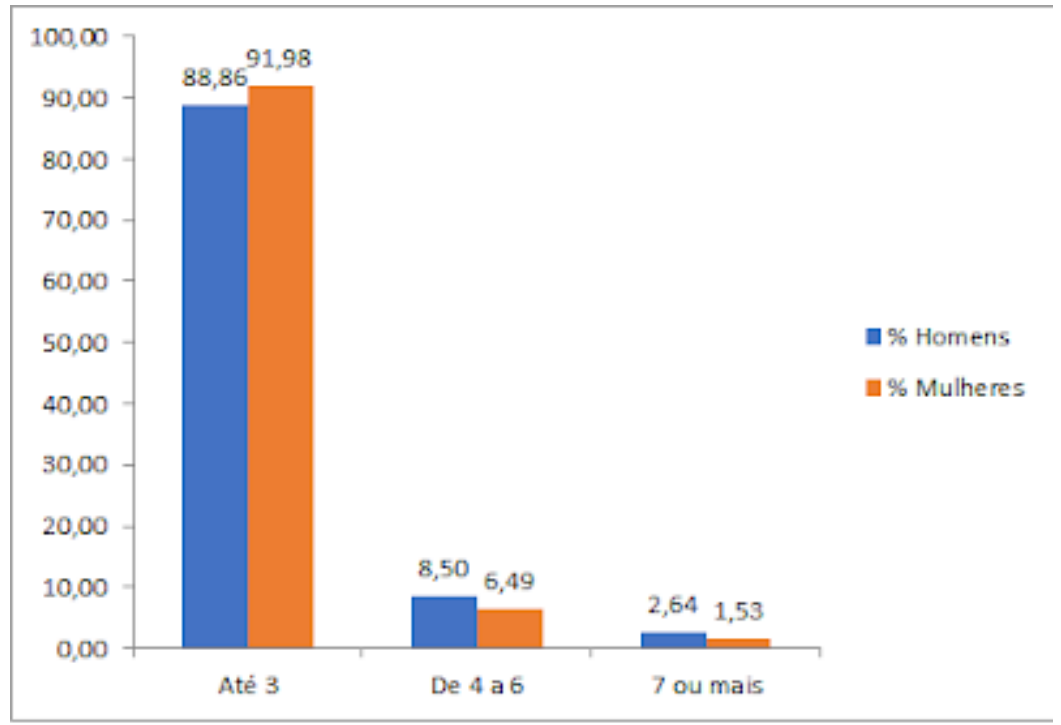

FONTE: O autor (2020).

A dificuldade que as mulheres enfrentam em exibir um maior número de filmes nas salas de cinema brasileiras ficou um pouco mais evidente quando analisei a participação de homens e mulheres entre os cineastas mais profícuos neste período. Em primeiro lugar identifiquei os cineastas, independente de sexo, que lançaram sete ou mais filmes no mercado. $\mathrm{O}$ resultado que encontrei revelou 27 homens e apenas quatro mulheres. Entre os homens, seis diretores lançaram dez ou mais filmes. O que conseguiu o maior número de filmes foi Robeto Santucci com 14. Este foi seguido por Evaldo Mocarzel com 13 e Andrucha Waddington com 12. Por outro lado, entre as mulheres, Lucia Murat foi a que lançou o maior número, dez filmes. Em segundo lugar esteve Tizuka Yamasaki com oito filmes, seguida por Cris D'Amato e Sandra Werneck com sete filmes cada uma. 
Para poder fazer uma comparação mais precisa, utilizei as 21 diretoras com quatro ou mais filmes exibidos entre 1995 e 2019. Como pode ser visto na tabela 2, a média dos filmes lançados pelos homens deste grupo foi de 8,5 filmes, enquanto a das mulheres foi de 5,3. Ou seja, além das mulheres serem um conjunto bem menor do que o dos homens que lançaram filmes produzidos no Brasil, estas têm maior dificuldade de serem mais assíduas no mercado.

Tabela 2 - Diretores e Diretoras com maior número de filmes exibidos

\begin{tabular}{l|l|l|l}
\hline Homens & Filmes & Mulheres & Filmes \\
\hline Roberto Santucci & 14 & Lucia Murat & 10 \\
\hline Evaldo Mocarzel & 13 & Tizuka Yamasaki & 8 \\
\hline Andrucha Waddington & 12 & Cris D'Amato & 7 \\
\hline Moacyr Góes & 11 & Sandra Werneck & 7 \\
\hline Daniel Filho & 10 & Daniela Thomas & 6 \\
\hline Domingos de Oliveira & 10 & Julia Rezende & 6 \\
\hline Beto Brant & 9 & Lina Chamie & 6 \\
\hline Eduardo Coutinho & 9 & Tata Amaral & 6 \\
\hline Jorge Furtado & 9 & Anna Muylaert & 5 \\
\hline José Joffily & 9 & Izabel Jaguaribe & 5 \\
\hline Julio Bressane & 9 & Laís Bodanzky & 5 \\
\hline José Eduardo Belmonte & 8 & Maria Augusta Ramos & 5 \\
\hline Sergio Rezende & 8 & Carla Camurati & 4 \\
\hline Bruno Barreto & 7 & Claudia Priscilla & 4 \\
\hline Gabriel Mascaro & 7 & Eliane Caffé & 4 \\
\hline Guto Parente & 7 & Helena Solberg & 4 \\
\hline Heitor Dhalia & 7 & Mara Mourão & 4 \\
\hline Helvécio Ratton & Marília Rocha & 4 \\
\hline José Alvarenga Jr. & Monique Gardenberg & 4 \\
\hline
\end{tabular}




\begin{tabular}{|c|c|c|c|}
\hline Murilo Salles & 7 & Rosane Svartman & 4 \\
\hline Paulo Nascimento & 7 & Susanna Lira & 4 \\
\hline Paulo Thiago & 7 & \multirow{3}{*}{$\begin{array}{l}\text { Média de Filmes - } \\
\text { Homens }\end{array}$} & \multirow{3}{*}{8,5} \\
\hline Ricardo Pretti & 7 & & \\
\hline Toni Venturi & 7 & & \\
\hline Ugo Giorgetti & 7 & \multirow{3}{*}{$\begin{array}{l}\text { Média de Filmes - } \\
\text { Mulheres }\end{array}$} & \multirow{3}{*}{5,3} \\
\hline Walter Carvalho & 7 & & \\
\hline Walter Salles & 7 & & \\
\hline
\end{tabular}

Fonte: $\mathrm{O}$ autor (2020).

Para 1.849 filmes brasileiros lançados no período, havia informação sobre o público alcançado e as empresas que fizeram a distribuição para as salas de cinema. Desse conjunto, 78,5\% foram dirigidos ou codirigidos por homens. A direção ou codireção de mulheres foi identificada em $16,1 \%$ dos filmes e, por fim, a codireção mista em $5,4 \%$ dos filmes.

Os dados sobre o desempenho de público dos filmes permitem expor outra desigualdade entre mulheres e homens nesse mercado que está associada ao acesso ao mercado distribuidor. Em primeiro lugar, entre os 91 filmes que tiveram mais de um milhão de espectadores, apenas $11(12,1 \%)$ foram dirigidos por mulheres e um teve codireção de mulher e homem. Na faixa de público entre 100 mil e um milhão de espectadores (233 filmes), a mulheres tiveram uma participação proporcional um pouco maior com 32 filmes (13,7\%). Nessa faixa a codireção mista foi de seis filmes. 437 filmes compuseram o conjunto daqueles que tiveram entre 10 mil e 100 mil espectadores. A presença das mulheres nesse grupo foi de 13,3\% (58 filmes), com 16 (3,7\%) em codireção mista. Por fim, entre os 1.088 filmes com menos de $10 \mathrm{mil}$ espectadores, a presença feminina na direção foi de 203 filmes $(18,6 \%)$ e $69(6,3 \%)$ em direção mista. Ou seja, a participação feminina cresce conforme o número de espectadores diminui. 
Este desempenho, em hipótese alguma pode ser atribuído à menor qualidade dos filmes dirigidos por mulheres em comparação aos filmes dirigidos por homens. Em meu entendimento, há duas variáveis que podem explicar a maior parte desta diferença: gênero dos filmes e empresa distribuidora. Quanto ao gênero dos filmes, os dados disponíveis os classificam em três categorias: animação, documentário e ficção ${ }^{2}$. Em geral, os filmes de documentário costumam ter menos público que as outras duas categorias. Para os filmes com informação sobre público, a média de público dos documentários foi de 8.080 espectadores enquanto a dos filmes de ficção foi de 298.131 espectadores.

Por outro lado, no que diz respeito à distribuição, há empresas muito grandes, que têm maior participação de mercado e outras muito pequenas com pequena participação de mercado. A possibilidade de maior público é, em geral, maior quanto maior for o poder de distribuição da empresa.

Em relação à primeira variável, enquanto os homens dirigiram mais filmes de ficção $(66,5 \%)$, as mulheres, embora também com maior presença na direção de ficção, tiveram 51,3\% de seus filmes nesta categoria. Por outro lado, no que diz respeito a documentários, este gênero representou $48,0 \%$ dos filmes dirigidos por mulheres e 31,8\% dos filmes cuja direção foi de homens. Nessa direção, Holanda (2017a, p. 50) afirma que "o documentário funda o Cinema Moderno de autoria feminina no Brasil. Ainda, mais à frente (p. 50), ao comentar aspectos característicos da direção feminina no cinema brasileiro, apresenta "o marco fundante do cinema brasileiro de autoria feminina, o documentário A entrevista (Helena Solberg, 1966). Assim, o desempenho de público mais favorável aos homens pode ser, em parte, devido a esta diferença. A tabela 3 apresenta os dados para os diferentes gêneros de filmes e tipos de direção.

2 Há apenas um filme classificado como vídeo musical neste período. Para fins de análise este foi incluído na categoria de documentário 
Tabela 3 - Gênero de filmes e tipos de direção

\begin{tabular}{l|l|l|l|l|l|l|l}
\hline Direção & Animação & $\%$ & Documentário & $\%$ & Ficção & $\%$ & Total \\
\hline Homem & 25 & 1,7 & 462 & 31,8 & 965 & 66,5 & 1452 \\
\hline Mulher & 2 & 0,7 & 146 & 48,0 & 156 & 51,3 & 304 \\
\hline Mista & 2 & 2,1 & 55 & 59,1 & 36 & 38,7 & 93 \\
\hline Total & 29 & 1,6 & 663 & 35,9 & 1157 & 62,5 & 1849 \\
\hline
\end{tabular}

Fonte: $\mathrm{O}$ autor (2020).

$\mathrm{Na}$ questão da distribuição, parece haver uma barreira de acesso às grandes distribuidoras que dificulta que os filmes dirigidos por mulheres tenham uma presença mais significativa de mercado. Para ilustrar este ponto, na tabela 4 apresento os dados sobre as maiores distribuidoras presentes no mercado brasileiro entre 1995 e 2019.

Tabela 4 - Distribuidoras com maior participação no mercado, filmes, público e tipo de direção

\begin{tabular}{l|l|l|l|l|l}
\hline Distribuição & $\begin{array}{l}\text { Direção } \\
\text { masculina }\end{array}$ & $\begin{array}{l}\text { Direção } \\
\text { feminina }\end{array}$ & $\begin{array}{l}\text { Direção } \\
\text { mista }\end{array}$ & $\begin{array}{l}\text { Total de } \\
\text { filmes }\end{array}$ & $\begin{array}{l}\text { Percentual } \\
\text { do público } \\
\text { atingido }\end{array}$ \\
\hline Downtown/Paris & 79 & 10 & 2 & 91 & 29,0 \\
\hline Fox & 34 & 7 & 1 & 42 & 9,6 \\
\hline Columbia & 34 & 2 & 1 & 37 & 9,5 \\
\hline Warner & 37 & 3 & 1 & 41 & 6,7 \\
\hline Imagem & 59 & 10 & 0 & 69 & 5,8 \\
\hline Downtown/Paris & 8 & 0 & 0 & 8 & 4,8 \\
\hline RioFilme & 20 & 1 & 0 & 21 & 3,4 \\
\hline Paris & 5 & 0 & 0 & 5 & 3,3 \\
\hline Zazen & 15 & 1 & 0 & 16 & 3,2 \\
\hline Total & 291 & 34 & 5 & 330 & 75,3 \\
\hline & & & & &
\end{tabular}




\begin{tabular}{l|l|l|l|l|l}
\hline Proporção & $88,2 \%$ & $10,3 \%$ & $1,5 \%$ & $100,0 \%$ & - \\
\hline
\end{tabular}

Fonte: elaborado pelo autor, 2020.

Pela tabela 4, percebe-se que $75,3 \%$ do público total dos cinemas entre 1995 e 2019 foram alcançados por nove distribuidoras que atuaram isoladamente ou em codistribuição com uma ou duas outras empresas. A parceria entre a Paris e a Downtown representou $29,0 \%$ do mercado com 91 filmes distribuídos, dos quais apenas $11 \%$ foram dirigidos exclusivamente por mulheres. Fox e Imagem foram as distribuidoras que tiveram maior proporção de filmes dirigidos por mulheres, $16,7 \%$ e $14,5 \%$ respectivamente. No conjunto, os filmes dirigidos por mulheres representaram apenas 10,3\% dos filmes distribuídos pelas maiores empresas do mercado. Este número é 5,8 pontos percentuais menor do que a presença das mulheres no total de filmes distribuídos nestes 25 anos (16,1\%). Ou seja, as mulheres têm maiores dificuldades em colocar seus filmes para distribuição pelas maiores empresas do mercado.

Em síntese, os dados analisados evidenciam uma pequena participação das mulheres na direção de filmes brasileiros, ao mesmo tempo em que revelam um pior desempenho médio em termos de público para os filmes dirigidos pelas mulheres. Na próxima seção, analiso os discursos de algumas cineastas para tentar perceber como elas veem seu papel no mercado do audiovisual brasileiro.

\section{A construção do papel de direção pelas mulheres}

Nesta seção, apresento trechos dos discursos das mulheres entrevistas por Nagib (2002). Sigo a ordem da apresentação dos depoimentos que consta no livro (alfabética por sobrenome). Esses depoimentos, conforme alertou Lúcia Nagib no capítulo de apresentação do livro, foram construídos a partir de questões colocadas a todas e todos os entrevistados, cujo tom deveria ser "como entendo o ato de fazer cinema" (NAGIB, 2002, p. 21). 
A primeira, Tata Amaral (Márcia Lellis de Souza Amaral), que à época do livro, havia realizado, em 1997, Um céu de Estrela, reflete sobre sua experiência como militante anti-ditadura e os esforços de estudo que sua formação como militante demandou. Assim, aponta uma questão importante na prática da realização cinematográfica:

Estimulou-me a ter método, disciplina, algo que uso muito no cinema. Desde muito cedo, aprendi na prática a trabalhar com projeção, análise, balanço, coisa que em cinema também usamos muito. Para fazer um filme é preciso uma estratégia, um planejamento econômico (p. 42)3.

Eliane Caffé (Eliane Dias Alves), ao final de seu depoimento, aborda uma questão que julgo central para o entendimento das dificuldades enfrentadas pelo cinema brasileiro, seja ele feito por mulheres ou homens, Ela tratava da questão da falta de uma política mais ampla de estímulo à produção cinematográfica no Brasil e, comentando sobre seu primeiro longa, de 1998, diz:

Kenoma é exemplo de um problema que vivemos hoje em dia no Brasil - e o cinema europeu também vive isso, que é a questão da distribuição e exibição. O filme foi distribuído pela Riofilme, lançado com três cópias, em São Paulo, Rio e Belo Horizonte. É uma loucura! São R\$ 1,7 milhão investidos num filme, eu passo três, quatro anos trabalhando, e o filme é lançado com três cópias num território enorme como o do Brasil. É quase como enterrá-lo num cemitério! E isso é uma contradição. $\mathrm{Na}$ medida em que tivemos a retomada da produção, $\underline{\text { a }}$ questão da exibição tornou-se muito mais problemática e urgente (p. 136) ${ }^{4}$.

Carla Camurati (Carla de Andrade Camurati), cujo filme Carlota Joaquina, princesa do Brasil (1995) é um dos símbolos da

\footnotetext{
3 Todas as citações literais desse ponto em diante são de Nagib (2002) e os grifos são meus.

${ }^{4}$ Esta questão do número de cópias de um filme é extemporânea hoje em dia. No entanto, como evidenciei na seção anterior o acesso ao mercado distribuidor é uma barreira maior às mulheres.
} 
retomada do cinema brasileiro nos anos 90 do século passado, chama a atenção para o fazer coletivo dessa arte/indústria:

o legal do fazer cinematográfico é exatamente o envolvimento e a cumplicidade de um grupo com relação a um tema, É claro que, quando se dirige, é preciso, como a palavra diz, direcionar a equipe. Mas a efervescência desse fazer está no trabalho conjunto (p. 147).

Na fala de Monique Gardenberg, outra dimensão significativa do trabalho no cinema brasileiro é salientada. Para ela, no Brasil, "é saudável que o cineasta tenha uma segunda profissão, porque é muito difícil fazer cinema. Como não quero mudar de país, procuro outras atividades, como fazer videoclipes... Cada um deve criar uma filosofia de produção compatível com a sua pessoa, senão vem a amargura" (p. 219). Esta fala é ecoada em Holanda (2017a, p. 20), quando sintetiza entrevista com Olga Futemma sobre sua trajetória no cinema brasileiro: "Olga Futemma tem consciência de que foi cineasta só de vez em quando".

O depoimento de Bia Lessa (Beatriz Ferreira Lessa) surge no livro junto com o de Dany Roland (David Roland Pinto), visto que codirigiram Crede-mi (1997). A prática da codireção, tem se tornado cada vez mais usual no cinema brasileiro. Um aspecto no depoimento de Bia Lessa que me chamou a atenção foi sobre a incerteza de se chegar a uma história fílmica, em especial na realização de documentários. A dificuldade da montagem, parte fundamental do fazer fílmico, pode ser angustiante, mas também prazerosa. Ela conta:

Na hora da montagem do filme, não sabíamos se ia dar uma história ou não. Mas daí houve um fato decisivo, que foi aquele velhinho do começo do filme... ele me perguntou por onde começar. Eu disse: "Pelo princípio". Então ele começou a recitar o Gênesis: "Quando Deus criou o céu e a terra" ... Daí quando a gente foi montar o filme, e queríamos saber por onde começar, a resposta foi essa: do princípio... Daí transformou-se num exercício de 
$\underline{\text { montagem delicioso }}$ e podíamos jogar fora o que era óbvio (p. 262-263).

No depoimento de Mirella Martinelli que, à época tinha feito, em codireção com Eduardo Caron, Terra do Mar (1997), surge a dimensão do sucesso/fracasso em relação às expectativas criadas no processo de realizar um filme. Em especial, de como essa dimensão, seja como fracasso ou sucesso, pode ser multifacetada, envolvendo desde questões quantitativas (público e renda, por exemplo) até a recepção do filme, seja pela crítica ou pelos espectadores:

quando se faz cinema, é sempre aquela expectativa de glamour, de sucesso, prêmios, festivais, tudo isso que, no fim, é uma grande ilusão... Já sabíamos que não ia ser de grande público, por ser um documentário..., mas tivemos uma ótima resposta de público. Não fomos aceitos na grande maioria dos festivais, mas das pessoas que viram, muitas vieram procurar a gente para dizer como ficaram relaxadas, harmoniosas, como se sentiam bem assistindo o filme (p. 291-292).

Para Susana Moraes (Susana de Mello Moraes), diretora de Mil e uma (1995), o interesse maior está centrado na forma de contar histórias e, não propriamente, na história em si (p. 311). Nesse sentido, ela ao comentar a política de fomento à implantação de uma indústria de cinema no Brasil, argumenta que "quanto maior a produção de filmes, maior o espaço para se fazer um cinema que me interessa mais, com experimentalismo, num caminho mais autoral. O cinema é uma individualidade, a ambição de um autor..." (p. 311, grifo meu).

Mara Mourão (Mara Matilde Cardoso Mourão) percebe a função do cineasta como multifacetada. Refletindo sobre sua trajetória, logo após a produção de Alô! (1998), seu primeiro longa, ela comentava sobre sua vida muito relacionada às artes em geral, gostando de tudo um pouco. Em seu depoimento ela diz que:

o cineasta é isso, um pequeno maestro que tem um pouco de dom para tudo, mas não tem um dom específico. $\mathrm{O}$ cineasta é uma pessoa multifacetada, 
principalmente aqui no Brasil, onde tem que ser além de tudo, captador de recursos e entender de finanças para tocar seu filme (p. 318).

Quando fez seu depoimento, Lúcia Murat (Lúcia Murat Vasconcelos) já tinha uma história de dois longas e dois curtas. Doces Poderes (1996) é seu filme da Retomada, no entanto, em 1989 ela já tinha lançado Que bom te ver viva. No depoimento de Lúcia Murat chama atenção a questão da formação para o cinema e a contribuição do movimento cineclubista. Ela comentava sobre sua relação com o cinema, e como esta foi se transformando ao longo de sua vida. Assim se expressa a cineasta:

Já na adolescência, foi a experiência do conhecimento. Nos anos 60, imperava o grande cinema, o Cinema Novo, a Nouvelle Vague. Pertenci à chamada "geração Paissandu", o nome do cinema onde passavam todos esses filmes. Para nós, $\underline{\mathbf{o}}$ cinema era uma maneira não apenas de conhecer o mundo, mas também de refletir sobre esse mundo. Não íamos ao cinema apenas para assistir ao filme, mas também para discutir o filme, o que fazíamos na saída. Havia também outros cineclubes onde isso se dava (p. 322).

Fabrízia Alves Pinto (Fabrízia Gontijo Alves Pinto), ao contrário de Lúcia Murat, estava iniciando sua trajetória no mundo do cinema, à época da Retomada. Em 1998, lançou Menino Maluquinho 2, a aventura. Ela vinha de uma trajetória de assistente de direção e coreógrafa em publicidade, e teve a oportunidade de fazer o longa de autoria de seu pai, Ziraldo, antes de dirigir filmes na publicidade. Em sua fala surge a questão da identidade de cineasta, bem como a relação com a publicidade:

Não me chamaria ainda de cineasta. É muito cedo; você faz um longa e já é cineasta? Ainda estou em processo de aprendizagem. Encaro a publicidade como uma faculdade de cinema. Cada vez que faço um comercial, faço cinema. Acho, contudo, que não 
tenho os vícios e maneirismos da publicidade, por ter começado ao avesso (p. 347).

Na fala de Monica Schmiedt, cuja participação na Retomada se deu com o filme Antártida, o último continente (1997), surge a questão da autoformação como cineasta e a junção com a função de produção. Originária do Rio Grande do Sul, seu depoimento também incorpora uma questão regional:

Toda essa geração que faz cinema no Rio Grande do Sul nesta última década é autodidata. Eu também. Aprendi cinema fazendo... Nunca fiz faculdade ou qualquer curso $^{5}$, embora tivesse gostado de fazer. Não sou essencialmente diretora, mas produtora, eis minha grande paixão. Sempre gostei de viabilizar projetos, não só de realizar projetos de outros diretores que vêm a mim para produzirmos juntos um filme, mas viabilizar ideias próprias. Essa é a vantagem do produtor que é também diretor: ele pode ter ideias (p. 444).

Helena Solberg (Maria Helena Collett Solberg) tem, também, uma trajetória longa no cinema brasileiro, com filmes exibidos desde começo da década de 70. Em 1995, ela participa da Retomada com Carmen Miranda, bananas is my business. Em seu depoimento, ela trata da fronteira entre documentário e ficção, por usar uma mistura dos dois gêneros em seu filme. Assim ela informa:

O filme é o que às vezes chamam de "docu-drama". Gosto muito dessa fronteira entre o documentário e a ficção, partindo do princípio de que todo filme traduz o ponto de vista de quem está atrás da câmera. Parti para a fantasia de uma Carmen falsa, quase inventada, quase como uma história de tabloide. Tudo isso evidentemente corre ao lado da história da pessoa real que acontece atrás das portas, algo que não pode ser contado e que Carmen

\footnotetext{
${ }^{5}$ Este aspecto é um que sofreu modificações nos últimos 15 anos. Houve uma proliferação de cursos superiores de formação em cinema que se reflete em uma nova geração de cineastas, homens e mulheres, oriundos desses cursos.
} 
na verdade não queria contar nem para si mesma ( $\mathrm{p}$. 463).

Para Rosane Svartman, cineasta de Como ser solteiro (1998), à época de seu depoimento (2002), o mercado cinematográfico era competitivo e o produto nacional tinha pouca proteção. Ademais, a experiência de seu filme exemplifica, mais uma vez, a questão do difícil acesso e permanência nas salas de exibição. Em suas palavras:

Como ser solteiro foi lançado junto com Titanic! Sofremos muito com isso. Tivemos um público bacana, mas fomos sempre tirados dos cinemas, ainda com média de sala... Se estou fazendo média de sala, de algum jeito tenho que poder ficar na sala (p. 468).

No trecho sublinhado, estava implícita a questão de como regular o mercado exibidor para garantir a entrada e permanência do filme nacional no circuito exibidor.

Na fala de Daniela Thomas (Daniela Gontijo Alves Pinto), há uma avaliação do período denominado Retomada do Cinema Brasileiro que apresenta certo caráter crítico. Seu filme, Terra Estrangeira, codirigido com Walter Salles, integra o conjunto de 14 filmes brasileiros lançados em 1995, marco inicial desse período. Para a cineasta:

esse renascimento do cinema brasileiro reflete profundamente a vida aqui em todos os seus aspectos políticos e culturais. É um cinema sem escola, um cinema sem nenhum vínculo ideológico, sem nenhuma discussão. É um renascimento quantitativo, ou seja, há filmes sendo feitos. Não existe um fórum de debates sobre o cinema. Simplesmente estamos fazendo filmes, e esse é o nosso único vínculo: estamos geográfica e temporalmente envolvidos (p. 484).

Mais à frente, ela adiciona uma temática à discussão que lembra o debate sobre o domínio de mercado por um tipo de cinema, mais industrial, em detrimento de outras maneiras de fazer filme. 
Daniela Thomas comenta que “o poder da Globo está tão arraigado que os filmes se transformaram num subproduto da dramaturgia global" (p. 484). Em oposição a este tipo de filme, ela aponta o que denominou "novo cinema independente", citando Tata Amaral, Paulo Caldas e Lírio Ferreira, Andrucha Waddington, Cláudio Torrres e Beto Brant (p. 484).

Sandra Werneck (Sandra Werneck Tavares de Souza) e Tizuka Yamasaki são as duas últimas cineastas com depoimentos registrados no livro de Lúcia Nagib. Ambas integram o grupo de cineastas mais experientes, com uma produção significativa de curtas e médias metragens antes de fazerem longas. No caso de Sandra Werneck, ela fez 12 curtas e médias entre 1976 e 1994. Tizuka Yamasaki, por outro lado, fez seis curtas entre 1974 e 1982, com seu primeiro longa, Gaijn, caminhos da liberdade, em 1980. Sandra Werneck, por outro lado, teve seu primeiro longa exibido em 2001, Amores possíveis. Tizuka Yamazaki teve dois filmes incluídos no período da Retomada conforme a visão de Lúcia Nagib: Fica comigo (1996) e O noviço rebelde (1997).

Das duas últimas cineastas, escolhi dois trechos que ajudam nessa compreensão qualitativa do que é fazer cinema sob a perspectiva de mulheres cineastas. Uma trata da questão da sensibilidade para a direção de atores e a outra trata, de novo, da distribuição e exibição. Dois pontos que, coincidentemente, mostram facetas distintas e igualmente importantes no fazer cinematográfico: a sensibilidade para a arte e a necessidade de compreensão do mercado:

Minha trajetória é marcada pelo documentário, sobretudo na área social e política... Essa minha trajetória me ajudou muito na ficção. No documentário, é preciso prestar atenção e registrar o momento da emoção. Essa capacidade ajuda muito quando se dirige atores (Sandra Werneck, p. 505).

O maior problema que encontramos é a distribuição e a exibição. Não temos uma distribuidora de 
impacto $^{6}$, que possa competir com os filmes que estamos entrando no mercado. A distribuição da produção cinematográfica brasileira ficou reduzida à Riofilme. $\mathrm{O}$ filme brasileiro fica uma semana em cartaz, só para mostrar serviço e sai (TIZUKA YAMASAKI, p. 515).

Os depoimentos constantes em Nagib (2002) e os trechos que selecionei para ilustrar esta seção apontam para uma grande diversidade de ideias e temas que fazem parte da construção de uma identidade de cineasta mulher no mercado brasileiro. $\mathrm{O}$ fazer cinema para as mulheres, em meu entender, é fruto de trajetórias de vidas distintas, resultando em olhares e questões peculiares a cada uma delas. No entanto, esse fazer cinematográfico exigiu que estas mulheres lidassem com aspectos artísticos e industriais de seu fazer. Algumas com mais sucesso, outras com menos, mas sempre tentando mostrar histórias por meio de imagens, afinal esta é a essência do cinema.

\section{Considerações finais}

Neste artigo, a partir de dados secundários, evidenciei que a presença de mulheres no cargo de direção de filmes brasileiros ainda é muito menor do que a de homens. Os dados relativos aos últimos 25 anos, apesar de mostrarem um gradual crescimento da presença feminina nesse campo, revelam a necessidade de ações e políticas públicas mais efetivas para a redução dessa desigualdade. No entanto, como comentaram Cisne e Gurgel (2008), pode ser que as políticas ou ações nessa direção sejam ainda caracterizadas apenas como pontuais, com uma contribuição mínima para a diminuição da desigualdade entre mulheres e homens, pois deixam de atuar sobre "as condições estruturais das desigualdades de gênero" (CISNE; GURGEL, 2008, p. 87).

$6 \mathrm{O}$ mercado atual de distribuição de filmes brasileiros conta com grandes empresas nacionais conforme apontei na seção anterior. 
No artigo abordei apenas a questão da direção de filmes brasileiros por mulheres. No entanto, a presença feminina nesta indústria se faz notar também em outras funções, tais como, roteiro, produção executiva, direção de fotografia e direção de arte. Um retrato mais completo poderia ser obtido ao considerar estas funções.

Ademais, é importante ressaltar que a visão das mulheres sobre o ofício de cineasta, neste texto, restringiu-se a depoimentos coletados entre final de 1998 e 2002. É de se imaginar que, com as mudanças por que passou o mercado do audiovisual no Brasil, inclusive com a entrada de uma nova geração de mulheres, a visão aqui retratada tenha sido parcial.

Assim, em função dessas limitações, estudos futuros poderiam explorar a participação da mulher no audiovisual brasileiro como um todo, em suas diversas funções. Esta abordagem pode se dar de forma quantitativa, por meio de análise dos dados existentes nas bases disponíveis. Mas, deve ser também explorada por meio de estudos qualitativos onde se ouça a voz das mulheres que estão exercendo esta miríade de funções no audiovisual brasileiro.

\section{Referências}

ALVES, Paula; ALVES, José Eustáquio Diniz; SILVA, Denise Britz do Nascimento. Mulheres no Cinema Brasileiro. Caderno Espaço Feminino, v. 24, n. 2, Uberlândia, p. 365-394, 2011.

ALVES, Paula; COELHO, Paloma Discursos, performatividades e padrões visuais no cinema: reflexões sobre as representações de gênero, o mercado cinematográfico e o cinema de mulheres. Aceno, Cuiabá, v. 2, n. 3, p. 159-176, 2015.

ANCINE - AGÊNCIA NACIONAL DE CINEMA. Participação feminina na produção audiovisual brasileira (2015). Rio de Janeiro: ANCINE, 2017a. 
ANCINE - AGÊNCIA NACIONAL DE CINEMA. Participação feminina na produção audiovisual brasileira (2016). Rio de Janeiro: ANCINE, 2017b.

ANCINE - AGÊNCIA NACIONAL DE CINEMA. Participação feminina na produção audiovisual brasileira (2018). Rio de Janeiro: ANCINE, 2019.

ARAÚJO, Luciana Corrêa de Cléo de Verberena e o trabalho da mulher no cinema silencioso brasileiro. In: HOLANDA, K.; TEDESCO, M. C. (Org.). Feminino e plural: mulheres no cinema brasileiro. Campinas: Papirus, 2017. p. 15-29.

BARBOSA, Neusa. Pioneiras na realização cinematográfica no Brasil. In: LUSVARGHI, L.; SILVA, C. V. da (Org.) Mulheres atrás das câmeras: as cineastas brasileiras de 1930 a 2018. São Paulo: Estação Liberdade, 2019.

CISNE, Mirla; GURGEL, Telma Feminismo, estado e políticas públicas: desafios em tempos neoliberais para a autonomia das mulheres. SER Social, Brasília, v. 10, n. 22, p. 69-96, 2008.

DESBOIS, Laurent. A odisseia do cinema brasileiro: da Atlântida a Cidade de Deus. São Paulo: Companhia das Letras, 2016.

GIMENEZ, Fernando Antonio Prado A competição na distribuição do cinema brasileiro de 1995 a 2017. Revista Livre de Cinema, v. 6, n. 2, Curitiba, p. 83-93, 2019.

HOLANDA, Karla Cinema brasileiro (moderno) de autoria feminina. In: HOLANDA, K.; TEDESCO, M. C. (Org.) Feminino e plural: mulheres no cinema brasileiro. Campinas: Papirus, 2017 a p. 43-58.

HOLANDA, Karla. Da história das mulheres ao cinema brasileiro de autoria feminina. Revista FAMECOS: mídia, cultura e tecnologia, Porto Alegre, v. 24, n. 1, p. 1-19, 2017b.

HOLANDA, Karla; TEDESCO, Marina Cavalcanti Feminino e mulheres no cinema brasileiro. Campinas; Papirus, 2017.

HOLLANDA, Heloísa Buarque de Prefácio. In: HOLANDA, K.; TEDESCO, M. C. (Org.) Feminino e plural: mulheres no cinema brasileiro. Campinas: Papirus, 2017. p. 7-8. 
NAGIB, Lúcia O cinema da retomada: depoimentos de 90 cineastas dos anos 90. São Paulo: Ed. 34, 2002.

NAGIB, Lúcia. Além da diferença: a mulher no Cinema da Retomada. Devires, Belo Horizonte, v. 9, n. 1, p. 14-29, 2012.

SCHVARZMAN, Sheila Gilda Bojunga: caminhos e percalços de uma afirmação. In: HOLANDA, K.; TEDESCO, M. C. (Org.) Feminino e plural: mulheres no cinema brasileiro. Campinas: Pairus, 2017. p. 1530 . 